\title{
Self-presentation processes in personal profiles in a pro-anorexia group
}

\section{Carolina Figueras Bates}

Universitat de Barcelona

Resumen

This paper presents the results of a content analysis of 1000 personal profiles posted on a pro-anorexia (proana) group from the social networking site Xanga. Applying methods of computer-mediated communication discourse analysis, the visual and verbal strategies of selfpresentation in pro-ana members' profiles were examined. Competence, ingratiation, exemplification and supplication emerged as the main self-presentation strategies identified in the text-based profiles. In contrast to other online self-presentations (such as personal home pages and weblogs), new contents and meanings related to a pro-ana social identity were assigned to these strategies in the group. The analysis of the profile pictures revealed that pro-ana users of the site tended to remain visually anonymous, resorting to images of models and celebrities, and reproducing the thin ideal. Based on these findings, this study advances some conclusions about how the pro-ana identity is constructed in social networking sites.

PALABRAS ClaVE: eating disorders, pro-anorexia, personal profiles, self-presentation, social networking sites, profile pictures
Abstract

This paper presents the results of a content analysis of 1000 personal profiles posted on a pro-anorexia (proana) group from the social networking site Xanga. Applying methods of computer-mediated communication discourse analysis, the visual and verbal strategies of selfpresentation in pro-ana members' profiles were examined. Competence, ingratiation, exemplification and supplication emerged as the main self-presentation strategies identified in the text-based profiles. In contrast to other online self-presentations (such as personal home pages and weblogs), new contents and meanings related to a pro-ana social identity were assigned to these strategies in the group. The analysis of the profile pictures revealed that pro-ana users of the site tended to remain visually anonymous, resorting to images of models and celebrities, and reproducing the thin ideal. Based on these findings, this study advances some conclusions about how the pro-ana identity is constructed in social networking sites.

KEY WORDS: eating disorders, pro-anorexia, personal profiles, self-presentation, social networking sites, profile pictures 


\section{INTRODUCTION}

The pro-anorexia (pro-ana) movement represents one extreme example of a Web social movement that defies the dominant medical models of diagnosis and treatment of eating disorders (Borzekowski et al., 2010; Fox et al., 2006; Giles, 2006; Mulveen and Hepworth, 2006). The movement adopts a strong anti-recovery position towards the condition (Fox et al., 2005), although heated discussions about anorexia and its meanings (whether it is a disease or a lifestyle) are frequent in pro-ana forums (Giles, 2006; Lipczyinska, 2007; Strife

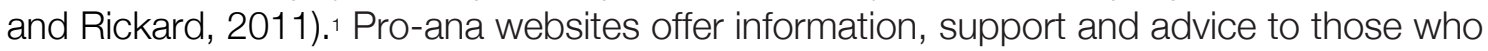
live or aspire to live with anorexia (Mulveen and Hepworth, 2006).

In spite of internal disagreements, the pro-ana movement meets the criteria of a virtual community, as stated in Herring's (2004a) framework of computer-mediated discourse analysis. Popular pro-anorexia online discussion forums show: a) an active and selfsustained participation by their members (Fox et al., 2006; Mulveen and Hepworth, 2006); b) shared values, culture, purpose and norms (Fleming-May and Miller, 2010); c) different roles and hierarchies among their users (Giles, 2006); d) solidarity and mutual support among the members (e.g., Brotsky and Giles, 2007; Ranson et al., 2010; Rodgers et al., 2012); e) self-awareness of the group as being distinctive from other groups (e.g., Boero and Pascoe, 2012; Dias, 2003; Whitehead, 2010); f) and criticism and resolution of conflicts within the group (e.g. Brotsky and Giles, 2007). Pro-ana members regard the online world as the only place where they can find acceptance and understanding of their practices and beliefs (Dias, 2003; Gavin et al., 2008).

The rapid proliferation of the pro-ana websites, and the potential harm that the material posted on those sites can cause to adolescents and young adults have prompted concern among professionals (see Sharpe et al., 2011), and a harsh condemnatory reaction in the media (see Rouleau and Ranson, 2011), which has led to the dismantlement of many proana websites. As a result, the pro-ana movement is evolving into other platforms, such as Facebook, MySpace or Xanga, in recent years (Juarascio et al., 2010; Whitehead, 2010), and phone applications, such as Instagram (Kenny 2013, Ging \& Garvey 2018). These mega-sites offer the possibility to engage in social networking with other pro-ana users, and provide a safe space in which individual and peer identities can be tested out, recreated and reinvented in different and novel ways from offline communication (Manago et al., 2008).

Applying the methodology of discourse and content analysis for new media, as developed by Herring (2004a) and (2004b), the purpose of the present study is to examine and identify the verbal and visual self-presentation strategies displayed by pro-ana members in their profiles on a popular social networking site (SNS) during the 2000s, called Xanga, that is no longer active.

Xanga was an Internet Web host launched in 1999 that provided its users with a combination of blogging and social networking features. Members of the 'Xanga community' could create their weblogs (personal journals), and could join other groups (blogrings) found in other SNS. Among the features hosted by Xanga, there was the creation of a personal profile. The user (called Xangan) chose a username, wrote a description of

\footnotetext{
${ }^{1}$ According to Strife and Rickard (2011), members of the community tend to draw a clear line between two kinds of anorexia nervosa: one denoting the clinical diagnosis of anorexia as a mental illness; the other referring to anorexia as a lifestyle chosen by the individual. This last type is known as 'ana'.
} 
himself/herself ('About me'), and uploaded a picture. A typical pro-ana profile posted in the Xanga group is provided in Figure 1:

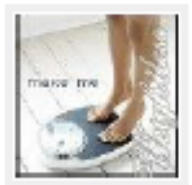

\section{Destination_Perfection_75}

You can call me Destination. Friend lock is on but feel free to add/sub me. Age: 17, Height: 5 foot 2 inches, Highest Weight: 138, Lowest Weight at height: 86 , Current Weight: See posts, Ultimate Goal Weight: 75

last updated - 3/5/2012

Figure 1. Profile image in context

\section{SELF-PRESENTATION IN ONLINE ENVIRONMENTS}

In his seminal work The Presentation of Self in Everyday Life, Goffman (1959) regards selfpresentation as a process of impression management. According to Goffman (1959), the impression management behaviors that an individual may strategically perform consist of two kinds of 'sign activity': expressions given (intended communication) and expressions given off (unintentional communication). In interacting with others, individuals tend to emphasize or to hide certain aspects of the self that do not accord to the norms or ideals of the group, in the hope of being accepted and well liked by others. An 'information game' ('performance', in Goffman's terms), whereby the person controls the information given and given off, is played in everyday communication. The need of being authentic, however, conflicts with impression management when individuals make decisions about selfdisclosure in personal relationships (Ellison et al., 2006).

As research on identity management has shown, different aspects of the self are expressed in different contexts. According to Higgins (1987), three domains of the self can be distinguished: the actual self (the representation of the attributes that the person actually possesses); the ideal self (the representation of the attributes that the person wishes or aspires to possess): and the ought self (the representation of the attributes the person feels obligated or in duty to possess). Applying Higgins' work on personality to their research on online relationships, Bargh et al. (2002) discovered that the online anonymity made easier the expression of the more negative aspects and attributes of the self, in comparison to face-to-face interactions. In the online dating environment, Ellison et al. (2006) found that online daters tended to create a profile reflecting their 'ideal self', as a compromised solution to balance the pressures of impression management and of showing the 'real' self to a potential partner. As Whitty (2007) remarks, although people feel the temptation of presenting a more attractive 'true self' in the online date scenario, they are also aware of the need of being more authentic with their 'actual self'.

While in the domain of the online dating sites individuals are more closely monitored about self-disclosure and authenticity (Ellison et al., 2006), in other web sources, such as weblogs, the level of anonymity can affect self-presentation processes. In the study conducted by Qjan and Scott (2007), bloggers who resorted to discursive anonymity (withholding identifying information) tended to self-disclose, whereas those who used visual anonymity (lack of a real image of the person) did not necessarily reveal more about themselves. Personal journal blogs showed higher levels of self-disclosure (Bortree, 2005), whereas if the blog had an open audience, or if it was being used to vent or express frustration, the user was more likely to remain anonymous. Conversely, type A-list bloggers, with a large 
online following, were more willing to provide personal information (Boyle and Johnson, 2010).

With the increasing popularity of SNSs in recent years, self-presentation has become a critical aspect in the way individuals relate and communicate to others. SNSs afford a set of tools to specifically carve out one's own digital impression (Manago et al., 2008), and provide their users with a wide range of opportunities to explore and to perform their identities in the virtual world (Salimkhan et al., 2010). Profiles are now the backbone of SNSs (Boyle and Johnson, 2010), and a regular discursive device for articulating and enacting one's identity online (Boyd and Heer, 2006). Users of megasites, such as Facebook or MySpace (and Xanga, when it was still active) can create a virtual identity through an individual profile that contains pictures and personal information, and check the personal profiles of other users. The profile owner controls and selects the level of selfpresentation and self-disclosure made available to the audience.

One significant aspect of the online display of identity on SNSs is the use of photographs. In online dating sites, profile pictures 'served to warrant or support claims made in textual descriptions' (Ellison et al., 2006: 14), whereas on SNSs visual impression management plays a decisive role in self-presentation (Salimkhan et al., 2010). The image 'acts as a form of representation', or more exactly, as a form of 'implicit identity construction' on SNSs (Strano, 2008: 2). The interest on how visual content contributes to self-presentation on SNSs has been growing in recent years (Hancock and Toma, 2009; Hall et al., 2012; Hum et al., 2011), with a focus on environment (anonymous vs nonymous contexts), gender (Siibak, 2009; Kapidzic and Herring, 2011) and age (Strano, 2008) differences. Little is still known, however, about visual and textual self-presentation and identity performance in non-conventional online groups, such as the pro-anorexia community.

\section{IDENTITY IN PRO-ANA WEBSITES}

A fundamental problem in addressing the issue of identity in pro-ana sites is that the researcher does not know who the participants are and 'what affiliation to the 'ana' identity means' (Hammersley and Treseder, 2007: 294). Besides, what pro-ana participants say in the online context may be shaped by what they imagine about their audience's reactions, and not a real reflection about themselves. In spite of these difficulties, researchers have identified some key components of the pro-ana identity. Giles' (2006) research has revealed that in the pro-ana universe there is a well established hierarchy of in-group identities whose limits, nonetheless, are strongly debated and contested: ana ('true' or 'pure' ana) is the most valued, followed by mia (short for bulimia), and, in a more marginal position, appears EDNOS (eating disorder not otherwise specified). Taking a feminist perspective, Day and Keys (2008) explored the construction of feminine identities on pro-ana websites, and found constructions such as 'the saint', 'the conformist' and 'the rebel' as subject positions adopted by users of these sites.

Relatedly, Gavin et al. (2008), investigating the presentation of pro-anorexia in one website, identified two dominant themes: 1) fostering a sense of the pro-ana self as abnormal; and, 2) maintaining the ana (anorexic) identity concealed from family and friends offline. More recently, Haas et al. (2011) concluded that the co-construction of an 'ana' personal identity involved resorting to two main strategies: 'staying true to ana', by self-disclosing extreme behaviors and practices for weight loss, and creating an 'audience for ana', by co-crafting a shared virtual social identity. 
In a complementary line of investigation, researchers have focused on the functions of 'body talk' (text-based descriptions about the body and bodily practices) in pro-ana sites and how this 'body talk' informs a pro-ana identity. Riley et al.'s (2009) study on recovery and eating disorder websites revealed that both sites promoted the thin ideal, included valid claims of group membership, and used talk about bodily experiences either to support a recovery or a pro-ana identity. Boero and Pascoe (2012), in turn, explored how authenticity and embodied practices were negotiated in pro-ana websites to police the boundaries of the community.

In the linguistic level, some differences between the words used for self-presentation in proeating disorders and recovery sites have also been established (Lyons et al., 2006; Wolf et al. 2007 and 2013). In the discursive level, Knapton (2013) and Figueras (2015) has highlighted some fundamental metaphors in pro-ana websites and online groups that define the pro-ana identity. More recently, researchers have focused on how pro-ana discourses are projected in image-based platforms such as Instagram (Ging \& Garvey 2018) to reify the ideal pro-ana self. Following this line of research, the purpose of the present study is to contribute to the analysis of the multimodal discourse used by pro-ana members to perform the self in SNSs. The overarching research question in this article is: how is self-presentation constructed and enacted in the personal profiles created in pro-ana SNS groups? In particular,

Will there be differences in self-presentation strategies in the personal profiles in a pro-ana community vs other Web sources of self-presentation?

Will the visual content on the pro-ana group profiles be different from other profile pictures on other SNS groups?

These questions are based on previous research on the particular communication strategies identified in pro-ana websites (Boero and Pascoe, 2012; Haas et al., 2011; Riley et al., 2009), the content material of pro-ana sites (Borzekowski et al., 2010; Juarascio et al., 2010; Norris et al., 2006; Sharpe et al., 2011; ), the self-presentation strategies on cyberspace (Dominick, 1999; Bortree, 2005; Papacharissi, 2002), and the visual analysis of SNS profiles (Hankock and Toma, 2009; Hum et al., 2011; Kapidzic and Herring, 2011).

\section{METHODOLOGY}

\subsection{Data Sample}

Methodologically, this study is based on an unobtrusive sampling of language from the Internet. The data from the personal profiles were obtained through a search of the Xanga site, the key phrases being 'pro-ana', 'pro-eating disorder', 'weight loss', 'weight issues', 'thin', and 'thinspiration', and by following links from groups already identified. After examining several Xanga groups, the data were drawn from one of the largest Xanga groups (9294 members at the time of the sample), called Alice in Hungerland. 1000 profiles posted in different time periods since the group was created in 2006 were selected by ordering alphabetically the profiles. The final sample, collected at the end of June of 2011, consisted of 725 text profiles (with no picture), and 884 profile images (with no text).

The demographics of the sample were difficult to ascertain, since few users provided personal information in their profiles. Gender (female) could only be established in 57 profiles. When age was specified, the user was a teenager or a young adult (113 cases). In 
spite of the lack of information, we can conservatively assume that most pro-ana members in the group were female teenagers and young adults. Xanga is a popular SNS with 12-17 year olds (Boyle and Johnson, 2010), and pro-ana users tend to be female teenagers and young adults (Lyons et al., 2006).

\subsection{The analytical approach}

Methods of discourse and content analysis were applied to the data collected from the Xanga profiles. The framework for this analysis was Herring's Computer-Mediated Discourse Analysis (CMDA), as developed by Herring (2004a, 2004b). The CMDA process involves the following steps: 'articulating the research question'; 'selecting the computermediated data sample'; operationalizing 'key concept(s) in terms of discourse features'; selecting and applying 'method(s) of analysis'; and interpreting results (Herring, 2004a: 24).

Pro-ana profiles were examined both in the textual and in the visual dimensions. For the operationalization of the key concept 'self-presentation' in the textual dimension, the categories of self-presentation described by Jones (1990) were adapted and used. To measure self-presentation in the visual dimension, three of the categories applied by Kapidzic and Herring (2011) to uncover gender differences on self-presentation in teen chatrooms (social distance, behavior and dress) were applied, and one (body shape) was added.

Textual self-presentation strategies. The profiles were analyzed according to Jones' (1990) classification of self-presentational strategies, as applied by Dominick (1999) in his study of personal home pages, and Bortree (2005) in her research on teenage girls' weblogs. Jones' (1990) categories are ingratiation (defined as the strategy used to be liked by others), competence (related to self-promotion; it serves the purpose of portraying the subject as skilled and accomplished), intimidation (the person seeks to be perceived as having power over others), exemplification (the subject intends to be judged as morally superior, or adhering to higher ethical standards or religious beliefs), and supplication (the person appears helpless so that others can come to help and rescue him/her).

Visual content. The profile pictures in the sample were also coded for their visual content. Previous content analysis of pro-ana websites concluded that almost $80 \%$ of the images and the prose in pro-ana websites were selected to inspire weight loss (Borzekowski et al., 2010). Based on these findings, the basic assumption for the analysis was that the profile photographs would contain thinspirational material, that is, fashion and advertising visual imagery inspiring the thin ideal, instead of real pictures of the users. Thinspirational visual content was defined by the use of pictures of fashion models or popular actresses exhibiting a very slender figure. Accordingly, degree of thinspirational content of the images was measured with four variables: social distance, behavior, dress, and body size.

The variable social distance, originally operationalized by Kress and van Leewen (1996), is related to the notion of proxemics. Social distance can adopt one the following six values: intimate (showing only the face or head), close personal distance (head and shoulders), far personal (from the waist up), close social (the whole figure is shown), far social (the whole figure with space around it), and public (torso of at least four or five people).

The variable behavior is based on Goffman's (1979) analysis of the ways in which gendered bodies are represented in magazine advertisements. Combining Goffman's observations 
with Kress and van Leewen's semiotics, Bell (2001) distinguished four values in the variable behavior: offer/ideal, demand/affiliation, demand/submission, and demand/seduction.

Profile images were also coded for the variable dress. Categories of sexual dress were initially developed by Soley and Reid (1988), and applied by Lambiase (2003) to examine the combination of sex, celebrity and marketing on the Web. The values for this variable were: demure (everyday dress), suggestive (partially exposing upper body, or wearing short shorts or short skirts), partially clad (wearing underwear or swimsuits), and nude (Lambiase, 2003).

The analysis of thinspirational visual material required complementing the variable sexual dress with the variable body size, measured according to the Contour Drawing Rating Scale devised by Thomson and Gray (1995). The scale comprises nine male and nine female 'front-view contour drawings of precisely graduated sizes (Drawing 1, the thinnest; Drawing 9, the largest)' (Thomson and Gray, 1995: 263). This psychometric instrument was used by Sypeck et al. (2004) to assess the evolution of body size for fashion models in American magazines from 1959-1999.

The issue of reliability establishing differences among the categories was addressed by coding twice a subsample of 100 personal profiles (about 10\% of the sample) with an interval of 10 days between coding sessions. The coding yielded identical results for both sessions, which indicated that the categories applied could be clearly differentiated.

\section{RESULTS AND DISCUSSION}

\subsection{Textual self-presentation strategies}

Few users provided any personal information in the textual self-description that could identify them. The majority of the weblogs in the pro-ana group linked to the profiles was protected with signing lock, to hide identity from family and friends (as several users openly recognized in their profiles). The usernames never contained the real name.

Some members of the group, however, provided certain general information about themselves, such as their first name, age, education, country, gender, interests, likes and dislikes, or hobbies. This result seems in line with the general function of SNSs as a forum for public presentation and assertion of personal traits (Lampe et al., 2007). In spite of these apparent signs of self-disclosure, most pro-ana Xanga members were extremely cautious about keeping their profiles anonymous, compared to members of other groups on SNSs (see Boyle and Johnson, 2010, for MySpace users). This reluctance to provide any private information is in accord to the fact that the profiles are open to a mass and unknown audience (Bortree, 2005), in which family members and friends may be included. To avoid being exposed, pro-ana members actively cloaked themselves to anonymity.

While pro-ana members were articulating their self-presentation without any personal information to avoid public exposition, they were also introducing themselves to other peers in the pro-ana community. To target this more restrictive and selective audience, pro-ana users resorted to four self-presentation strategies: competence, ingratiation, exemplification and supplication (see table 2). Jones'(1990) category of intimidation was not found relevant in the sample. 
Self-presentation processes in personal profiles in a pro-anorexia group | C. Figueras

Table 1. Self-presentation strategies results in the pro-ana Xanga profiles ( $N=725)$

\begin{tabular}{|l|l|l|l|}
\hline Competence & Ingratiation & Exemplification & Supplication \\
\hline 274 & 203 & 153 & 95 \\
$38 \%$ & $28 \%$ & $21 \%$ & $13 \%$ \\
\hline
\end{tabular}

Competence, the most common strategy in the sample, was used to present oneself as skilled to others. Bortree (2005), in her analysis of personal weblogs, found that teenage girl bloggers employed this strategy to present themselves as socially competent. In the pro-ana Xanga group, competence became a main discursive tool to give off the impression of being a true and legitimate member of the pro-ana community.

Many members of the group strived to present themselves as experts in the domain of eating disorders, showing experience in practices ('I was eating disordered for about 7 months. Then I binge ate July until November 2007') and knowledge in prescribed drugs and clinical terminology ('I'M A FAT PIG... WITH ADHD. WHO'S ON ADDERALL'). In particular, many users claimed to have a certain diagnosis, such as in (1-2), or a particular group identity (3-4):

(1) Diagnosed anorexic, Christian, loves music, reading, art, fashion, sewing, cooking, travelling, playing piano, playing guitar......I'm just me

(2) anorexic in 2004. Diagnosed eating disorder no otherwise specified in 2008. Obsessive compulsive disorder. Overachiever. Perfectionist.

(3) I am pro-anorexia. I am currently 18 years old and am a Senior in High School.

(4) Anorexic with bulimic tendencies. I've had an eating disorder for over 3 years

Medical diagnoses served in the profiles, as it has been found for other pro-ana sites, as 'marks of authenticity' or a 'matter of qualification' (Giles, 2006: 475). As Giles and Newbold (2011) argue, these specific claims about health status are sufficient to achieve accreditation and validation in the pro-ana group. In fact, in the pro-ana community, 'a member is accepted as 'ana' solely on the basis of convincing interaction' (Giles and Newbold, 2011: 420). Therefore, part of the credible pro-ana identity performance involved providing certain credentials about the experience of the anorexic condition.

Competence also involved efficient management of weight goals. In relation to this theme, up to $18 \%$ of the profiles in the sample contained the so-called signature in the pro-ana jargon; that is, statistics of height $(\mathrm{H})$, current weight $(\mathrm{CW})$, highest weight $(\mathrm{HW})$, lowest weight (LW), goal weight (GW), or ultimate goal weight (UGW):

(5) 5'3 HW:126 LW:98 CW:114 GW:96

(6) Stats: HW: 160s LW: 115 CW: 130 GW1: 115 (2/28/09) [ ] GW2: 108 (3/28/09) [ ] GW3: 100 (5/28/09) [ ] UGW: $90(6 / 28 / 09)[]$

Signatures became a rhetorical device enabling the user to perform a bodily identity, which simultaneously individualized and aligned her to the group rituals and standards. On the one hand, with this form of body talk, pro-ana Xanga members sought to create a 'sense of community through a sense of shared embodiment' (Ferreday, 2009: 198); on the other hand, the discursive elaboration of the self as weight was used as another tool of authenticity to claim an individual pro-ana identity (Riley et al., 2009). In fact, by showing knowledge and applying correctly the typographic conventions to provide the signature, the user was giving off the impression that she was an experienced member in the pro-ana community of practice. 
Following competence, the second most common strategy in the profiles was ingratiation (up to $28 \%$ of the users employed it). This strategy is usually applied to gain the affection, approval and recognition of others, and has been identified as the most common selfpresentation strategy in home pages (Dominick, 1999) and teenage blogs (Bortree, 2005). In contrast to these web sites, ingratiation adopted a distinctive and peculiar format in the pro-ana group. With this strategy, members of the group attempted to legitimize their belongingness to the group by sharing a repertoire of self-defeating feelings. In the pro-ana context, ingratiation required self-presenting in a negative way, emphasizing deficiencies and personal flaws, and expressing self-reproach and self-blame:

(7) I hate myself

(8) I am not important

(9) Fat

According to Haas et al. (2011), self-loathing constitutes one specific theme in the pro-ana websites. The authors identify two main types of self-loathing messages enacting this theme: loathing about one's physical body and loathing about one's inner being (Haas et al., 2011: 48). Both themes are present in the pro-ana Xanga profiles:

(10) Physical self-loathing: too fat; I'm big and fat and hate it; Such a fat dumbass... But not for long!!!

(11) Esteem self-loathing: I'm not important; I'm flawed; I suck; I'm a psychiatric mess

Indeed, descriptions of the self in the sample were built on claims about deficiencies that the person strongly felt compelled to change. This rhetoric was common in the pro-ana Xanga profiles, and functioned as a defining strategy to reinforce positive social identity. As Haas et al. (2011) point out, the self-deprecating exchanges between pro-ana are unique, in the sense that there is no attempt by other members of contradicting or challenging the self-loathing comments.

The third self-presentation strategy applied in the profiles was exemplification (21\% of the profiles). Exemplification was elaborated by pro-ana members with quotations, comments, and phrases that called for weight loss, glorification of beauty associated with thinness, and sacrifice and commitment dedicated to the pursuit of perfection (what is called 'thinspirational material' in the pro-ana jargon):

(12) The mirror is her enemy The scales, not her friend Bones to her are beautiful She'll starve until the end.

(13) No contact possible to flesh allayed the fever of the bone.

(14) I'd rather die thin and unhappy, then fat and unhappy...beautiful, control, and elegance...here I come.

(15) the only tactics I admire are do-or-die.

Exemplification appeared to be used to fuel the urge and determination to transform the current imperfect self into the ideal, flawless self dreamed by pro-ana members. By resorting to the self-presentation strategy of exemplification in the form of thinspirational prose, pro-anas aspired to engage themselves and others in the project of reaching the ideal self. As Norris et al., (2006) observed, 'thinspo' or 'thininspiration' material, a subcultural key feature of the pro-ana discourse, serves the purpose to motivate and maintain anorexic practices and behaviors.

Finally, supplication was adopted in $13 \%$ of the profiles, as a moving strategy to make friends, be accepted and get feedback from other members, seeking emotional support and specific advice for disordered eating. In the base for supplication there was always the wish, desire, aspiration or strong hope to better the current self through a radical body project (restricted to weight loss), embraced and shared by the group. This process of self- 
betterment was a demanding and relentless enterprise that required the constant encouragement by other members, who provided the support and the motivation to pursue the same ideals of physical and moral perfection; hence the calls for help and friendship as supplication self-presentation strategies in the profiles:

(16) trying to shed this shell of fat before heading off to college in the fall. i'm super nice, so let's be friends! let's help each other reach our goal $<3$

(17) I NEED support please ladies! Leave me a comment, I leave you a comment, very nice, do have friends lock just add me! HW: $127 \mathrm{CW}: 117 \mathrm{GW}: 110$ UGW: 105 BTW profile pic isn't me, but I wish ;0)

(18) Life goal: Be skinny. How's that for endearing? Yes--I use my own pictures. And I probably think you're beautiful. So be my friend, be my support. Find your strength. I could be yours.

(19) I'm Caroline. I wanna be beautiful like Kate. I wanna fit into the size 4 Chanel jeans. Help me in my fight to be beautiful. Help me through this disease, anorexia.

The use of supplication as a self-presentation strategy responded to the fostered sense of community and social integration that members of the group aimed to obtain. In this regard, several studies on content analysis of pro-ana forums have shown that social support is a central theme in some sites, and a key factor for active participation in the group (Brotsky and Giles, 2007; Juarascio et al., 2010; Mulveen and Hepworth, 2006; Ranson et al., 2010; Rodgers et al., 2012).

\subsection{Visual Content}

For the analysis of the visual content, 884 profile pictures were classified, according to the values for the variable social distance. $14 \%$ of the images were not representing human figures. Some common topics in these images were food, thinspirational prose, or natural landscapes.

Within the profiles pictures with human figures, 755 profile images depicted females, and only 4 men. Although it is difficult to determine with certainty, the majority of the profile pictures seemed not to portray the user, but a model or a celebrity. In some cases, the member overtly confessed that the picture was not of her: 'That is NOT me in the profile picture'. Only in 14 cases (2\%) it was explicitly recognized that the image was a real picture of the user: 'profile picture is me'; Profile picture is, and will always be me; 'I'm Winnie, this is my real picture'. The majority of pro-ana members, therefore, opted for visual anonymity in their profiles.

Results from the social distance variable analysis are presented in table 3.

Table 3. Social distance in the pro-ana Xanga profiles ( $N=884)$

\begin{tabular}{|l|l|l|l|l|l|l|l|}
\hline $\begin{array}{l}\text { No } \\
\text { human } \\
\text { picture }\end{array}$ & $\begin{array}{l}\text { Males } \\
\text { images }\end{array}$ & Intimate & $\begin{array}{l}\text { Close } \\
\text { personal }\end{array}$ & $\begin{array}{l}\text { Far } \\
\text { personal }\end{array}$ & Far social & Public & $\begin{array}{l}\text { Body } \\
\text { parts }\end{array}$ \\
\hline 128 & 4 & 130 & 140 & 179 & 140 & 52 & 111 \\
$14 \%$ & $.5 \%$ & $15 \%$ & $16 \%$ & $20 \%$ & $16 \%$ & $6 \%$ & $12.5 \%$ \\
\hline
\end{tabular}

It is noteworthy that, within the 130 users (15\%) who chose to present a human figure at an intimate distance (showing head or face), 37 of them (4\%) selected a photograph showing only part of the face (lips or eyes), and in 18 pictures (2\%) the eyes were covered. What is particularly interesting is the use of pictures in the profiles exposing certain parts of the body (12.5\% of the total). Torsos (5\%), abdomens (3\%) and legs (3\%) were the most prominent parts pictured in the profiles. 
It is also relevant to point out that few images (only 6\%) showed two or more people together, depicting a special occasion, as it is common, for instance, on females' profiles on Facebook (Strano, 2008). Instead of a more dynamic group identity, pro-ana members opted for a more static individual identity that emphasized media beauty and 'stood in' for the member's body in the virtual group.

For the analysis of the variable behavior, only in 583 images gaze and attitude were clearly visible (66\% of the sample). The most common images (32\%) were the ones depicting the offer/ideal behavior. Both idealized images of fashion models and pictures of body parts revealing extreme thinness were coded as instances of the offer/ideal behavior, as it was considered that the goal of these pictures was to model and to inspire an ideal of beauty.

Demand/seduction behavior (looking up or sideways at the viewer, head titled, body slightly angled) was represented in 11\% of the profiles. Demand/affiliation (looking at the viewer, smiling) was depicted in $10 \%$ of the profile pictures. Images of young girls looking at the viewer, but not smiling, or looking away in a kind of absent attitude, were included in the category of 'other' (12\% of the sample). Table 4 shows the results of this analysis.

Table 4. Summary of the results for the variable behavior in the pro-ana Xanga profiles ( $N=884$ )

\begin{tabular}{|l|l|l|l|l|l|}
\hline Offer/ideal & Demand/affiliation & Demand/seduction & Demand/submission & Other & NA \\
\hline 283 & 88 & 93 & 11 & 103 & 306 \\
$32 \%$ & $10 \%$ & $11 \%$ & $.1 \%$ & $12 \%$ & $35 \%$ \\
\hline
\end{tabular}

For the variable of dress, only 399 profiles could be analyzed. In the rest of images clothing was not visible. Results are presented in table 5 . The majority of the users in the pro-ana Xanga group (22\%) chose suggestive dress for the image in their profiles.

Table 5. Results from the image profiles for the variable dress $(N=884)$

\begin{tabular}{|l|l|l|l|l|}
\hline Demure & Suggestive & Partially clad & Nude & NA \\
\hline 102 & 192 & 87 & 18 & 485 \\
$12 \%$ & $22 \%$ & $10 \%$ & $2 \%$ & $55 \%$ \\
\hline
\end{tabular}

Lastly, for the variable body size, only in 205 images (23\% of the image profiles) the body, or parts of the body were visible enough to allow for a judgment about size. 77 images were coded as CD1 (contour drawing 1), and 115 as CD2 (contour drawing 2), which occupied the thinner end of the bodysize continuum scale devised by Thomson and Gray (1995). Both silhouettes were reported as being anorexic by raters in Thomson and Gray's (1995) study.

The analysis of the visual content of the profiles revealed that members of the group were extremely cautious about using their real pictures. This finding contrasts with the results obtained in previous research on dating sites and other networking sites, in which users carefully balance authenticity and self-enhancement when selecting the profile picture (Hancock and Toma, 2009). One factor in the concealment of real visual cues in the proana profiles might be the strong desire of hiding the eating disorder from friends and families. Competence in keeping the condition as a secret represents, as Gavin et al. (2008) argued, a key element of the online pro-ana identity.

The images portrayed an ideal version of the self, as advertised in commercials and magazines, and were purposefully used to hide user's true identity. The photographs also 
functioned to amplify and reinforce the pro-ana message of self-transformation articulated in the text. In the pro-ana profiles, the body was no longer a background text (as it is in advertising), but a foreground text put in place for the real body. That way, the individual's identity (a hallmark in SNS profiles) became a disappearing identity, overshadowed by the media ideals of success and beauty. This erasure effect was not just due to the fact that the photograph did not depict the user, but also to the selective set of visual features of the profile image.

Regarding, for instance, the social distance variable, pro-ana users preferred to show human figures in a wide range of different distances, with a slightly higher tendency towards far personal and far social distance, over intimate and close personal. These findings contrast with Kapidzic and Herring's (2011) observation that female users of teen chatrooms are more willing to portray themselves at intimate and close personal distances. However, they are consistent with Whitty's (2008) findings on the analysis of selfpresentation on online dating sites. Women, more often than men, tend to present 'an idealized version of themselves through 'glamour shots' ( $p$. 8). The images chosen by proana members of the group are intended to emphasize iconized beauty, to the extreme of substituting the own physical body for the slender Western bodily ideal. Thus, rather than using the photographs to visualize their looks, pro-ana users focused on the values and qualities that were important to them (see Ellison et al., 2006).

What is more, the distribution of social distance values in the sample seemed to suggest an emotional detachment of the user from the viewer, which was also manifested in the high percentage of photographs depicting an offer/ideal behavior, and with the person looking away and wearing suggestive clothing. Besides, resorting to images of bodies without a face, and, specifically the exhibition of those parts of the body that could show better how thin and/or fit the person was (abdomens and thighs), conveyed the message of objectification of the body, and by extension, objectification of the self. This form of bodyism is the most extreme practice of depersonalization (see Hall et al., 2012). If the self is conceived as an object, then it is susceptible to transformation. The profile photographs, in modeling an ideal identity, were aimed to model behavior.

\section{CONCLUSION}

This study has shown that personal profiles in a pro-ana group on a popular SNS are a relevant setting to explore particular practices associated with identity work and selfpresentation strategies in the pro-ana community. The analysis revealed that profiles in the Xanga pro-ana group were not mainly used for individual identity construction but for enacting a recognizable pro-ana identity. In fact, personal profiles became a perfect platform for playing a convincing discursive performance of being a 'true' ana, for negotiating public/private boundaries, and for building an audience that would engage in reading the weblog and interacting with the profile owner.

Members of the pro-ana group cautiously crafted their self-presentations by combining four main strategies: competence, ingratiation, exemplification and supplication. What was specific of the pro-ana profiles examined, in contrast to other online self-presentations, such as in teenage weblogs (Bortree, 2005) or in personal home pages (Dominick, 1999; Papacharissi, 2002), was the new content associated to these strategies and the different frequency of use of each one. Competence, as opposed to ingratiation, became the most important self-presentation mechanism in the profiles. It was aimed at granting acceptance and recognition from other members. By showing knowledge in medical diagnoses, 
management of the digital body (through the use of signatures), and by claiming a certain eating disorder identity (anorexia, 'pro-ana', 'mia', etc.), users showed their expertise in the pro-ana practices. Besides competence, articulating a description of the self based on selfdeprecation and self-loathing (the peculiar ingratiation strategy in the pro-ana profiles) and resorting in some cases to thinspirational statements (exemplification strategy) became also 'tools of authenticity', in terms of Boero and Pascoe (2012), to perform and validate a 'true' pro-ana identity. These findings confirm and extend previous research on communicative strategies and types of disclosure identified in pro-ana communities (Ferreday, 2009; Boero and Pascoe, 2012; Haas et al., 2011).

The presentational strategies applied by the pro-ana members were directly related to the structure of the self engineered in their profiles. Tensions between the actual, the ideal and the ought self were at the core of the self-descriptions. Pro-ana users devised a particular and unique strategy to manage these three aspects of the self. Instead of creating an ideal self (as is the case in online dating profiles; see Ellison et al., 2006), in the pro-ana profiles both ideal and actual selves were split between the text and the image. While the photographs depicted an impossible to reach ideal self, symbolically represented as the iconic figure of a young and thin fashionable woman (the beauty ideal publicized in the media), the text-based self-description dealt with the current self and, in some cases, introduced the ought self in the form of 'thinspirational' prose. The result was a dramatic confrontation between the full of imperfections current self, presented in the text, and the ideal, unattainable perfect self, portrayed in the image.

A critical component in this articulation of the self in the pro-ana profiles was the discursive construction of the body. The extensive use of weight signatures brought to the fore the importance of 'body talk' to negotiate identity and embodiment (Boero and Pascoe, 2012; Ferreday, 2009; Riley et al., 2009). Weight signatures, the main body talk introduced in the profiles, emerged simultaneously as individual identity claims and as group rituals that connected the user with the pro-ana community of practice and the pro-ana social identity (see Boero and Pascoe, 2012; Giles, 2006; Riley et al., 2009).

A complementary and specific tool to perform bodily enactment in the pro-ana Xanga profiles was, paradoxically, posting pictures that were not of the profile owner. With the careful selection of pictures of models and celebrities, pro-ana members went to the extreme in the common trend, among women, of providing an attractive profile photo of themselves representing more culturally normalized depictions of female beauty (Siiback, 2009; Strano, 2008, Whitty, 2007). This finding contrasts with what Boero and Pascoe (2012) observed in a pro-ana forum on MySpace, in which authenticity claims of being a 'true' pro-ana were made by posting real pictures of the user, and pictures of celebrities and models were fiercely contested as 'fake' and 'unreal'. Our results suggest that in public virtual spaces where pro-ana members actively try to remain anonymous, the tools of authenticity policing the boundaries of the community, commonly applied in more private sites, are not in place.

The analysis of the visual and verbal contents of the pro-ana Xanga profiles provides additional evidence for the idea, developed in contemporary work on embodiment and identity, that that the cyberspace is not a 'bodiless environment', but rather a scenario in which material bodies are strategically manufactured and enacted at will (Riley et al., 2009). More research is, however, still needed to explore the embodiment practices in pro-ana groups, both in the visual and the verbal dimensions, as performed in other new media (such as Instagram, Twitter or YouTube). 


\section{REFERENCES}

BARGH J., K. MCKENNA and G. FITTZSimons (2002): "Can You See the Real Me? Activation and Expression of the 'True Self' on the Internet», Journal of Social Issues, 58(1), 33-48.

BELL, P. (2001): "Content analysis of visual images», in van Leeuwen, T. C. and Jewitt, eds, Handbook of visual analysis, London, Sage, 10-34.

BOERO, N. and C.J. PASCOE (2012): «Pro-anorexia Communities and Online Interaction: Bringing the Pro-ana», Body and Society, 18, https://doi.org/10.1177/1357034X12440827

BORTREE, D.S. (2005): «Presentation of self on the web: An ethnographic study of teenage girls' weblogs», Education, Communication and Information, 5(1), 25-39.

BORZEKOWSKI, D., S. SCHENK, J. WILSON and R. PeEbles (2010): «e-Ana and e-Mia: A Content Analysis of Pro-Eating Disorder Web Sites», American Journal of Public Health, 100(8), 1526-1534.

BOYD, D. and J. HeER (2006): «Profiles as Conversation: Networked Identity Performance on Friendster", in Proceedings of the Hawaii International Conference on System Sciences (HICSS-39) January 4-7.

BOYLE, K. and T. JOHNSON (2010): "MySpace is your space? Examining self-presentation of MySpace users», Computers in Human Behavior, 26, 1392-1399.

BROTSKY, S. and D. GILES (2007): «Inside the 'Proana' Community: A Covert Online Participant Observation», Eating Disorders, 15, 93-109.

DAY, K. and T. KEYS (2008): "Starving in cyberspace: a discourse analysis of pro-eatingdisorder websites», Journal of Gender Studies, 17(1), 1-15.

DIAS, K. (2003): «The ana sanctuary: Women's proanorexia narratives in cyberspace», Journal of International Women's Studies, 4, 31-45.

DOMINICK, J. (1999): "Who do you think you are? Personal home pages and self-representation on the World Wide Web», Journalism and Mass Communication Quarterly, 76(4), 646-658.

Ellison, N., R. HeINO and J. GiBBS (2006): «Managing impressions online: Selfpresentation processes in the online dating environment», Journal of Computer-Mediated Communication, 11(2), article 2, http://jcmc.indiana.edu/vol11/issue2/ellison.ht $\underline{\mathrm{ml}}$

FERREDAY, D. (2009): Online Belongings: Fantasy, Affect, and Web Communities, Bern, Peter Lang AG.

FigueRAS, C. (2015): "“I Am a Waste of Breath, of Space, of Time": Metaphors of Self in a ProAnorexia Group», Qualitative Health Research,
25(2),

189-204, https://doi.org/10.1177/1049732314550004

Fleming-MAY, R. and L.E. MilleR (2010): “'I'm scared to look. But I'm dying to know': Information seeking and sharing on Pro-Ana weblogs», Proceedings of the American Society for Information Science and Technology, 47(1), 1-9.

Fox, N., K. WARD and A. O'Rourke (2005): «Proanorexia, weight-loss drugs and 'anti-recovery' explanatory model of anorexia», Sociology of Health and Illness. https://doi.org/10.1111/j.14679566.2005.00465.x

GaVIN, J., K. RODHAM, and H. POYER (2008): «The presentation of 'pro-anorexia' in online group interactions», Qualitative Health Research, 18, 325-333.

GILES, D. (2006): "Constructing identities in cyberspace: The case of eating disorders», British Journal of Social Psychology, 45, 463477.

GILES, D. and J. NEWBOLD (2011): «Self- and OtherDiagnosis in User-Led Mental Health Online», Communities Qualitative Health Research, 21(3), 419-428.

GING, D. and S. GARVEY (2018): “'Written in these scars are the stories I can't explain': A content analysis of pro-ana and thinspiration image sharing on Instagram», New, Media \& Society, 20(3), 1181-1200.

Goffman, E. (1959): The Presentation of Self in Everyday Life, New York, Doubleday.

GOFFMAN, E. (1979): Gender advertisements, London, Macmillan.

HAAS, S.M., M.E. IRR, N.A. JENNING, and L.M. WAGNER (2011): "Communicating thin: A grounded model of Online Negative Enabling Support Groups in the pro-anorexia movement», New Media and Society, 13(1), 40-57, https://doi.org/10.1177/1461444810363910.

HalL, P.C., J.H. West and E. Mclntyre (2012): «Female Self-Sexualization in MySpace.com Personal Profile Photographs», Sexuality and Culture, 16, 1-16, http://dx.doi.org/10.1007/s12119-011-9095-0.

HAMMERSLEY, M. and P. TRESEDER (2007): «Identity as an analytic problem: who's who in 'pro-ana' websites?», Qualitative Research, 7, https://doi.org/10.1177/1468794107078509

HancoCK, J.T. and C.L. TOMA (2009): «Putting Your Best Face Forward: The Accuracy of Online Dating Photographs", Journal of Communication, 59, 367-386.

HERRING, S.C. (2004a): "Computer-mediated discourse analysis: An approach to researching online communities», in Barab, S.A., R. Kling and J.H. Gray, eds., Designing for Virtual 
Communities in the Service of Learning Cambridge/New York, Cambridge University Press, 338-376.

HERRING, S.C. (2004b): «Content Analysis for New Media: Rethinking the Paradigm New Research for New Media», in Innovative Research Methodologies Symposium Working Papers and Readings, 47-66.

HIGGINS, E.T. (1987): "Self-discrepancy: A theory relating self and affect Psychological Review», 94, 319-340.

Hum, N.J., P.E. Chamberlin, B.L. Hambright et al. (2011): «A picture is worth a thousand words: A content analysis of Facebook profile photographs», Computers in Human Behavior, 27 , 1828-1833, https://doi.org/10.1016/i.chb.2011.04.003

JONES, E.E. (1990): Interpersonal Perception, New York, Freeman.

JuARAscio, A., A. ShoAiB and C.A. Timko (2010): «Pro-Eating Disorder Communities on Social Networking Sites: A Content Analysis», Eating Disorders, 18(5), 393-407.

KapidZIC, S. and S. HeRRING (2011): "Gender, Communication, and Self-Presentation in Teen Chatrooms Revisited: Have Patterns Changed?», Journal of Computer-Mediated Communication, 17, 39-59.

KENNY, M. (2013): «How Instagram has become the new hub for pro-anorexia and thinspiration culture», Pedestrian, 1 March, [en línea]:

https://www. pedestrian.tv/style/how-instagramhas-become-the-new-hub-for-pro-anorexiaand-thinspiration-culture/

KNAPTON, O. (2013): «Pro-anorexia: Extensions of ingrained concepts", Discourse and Society, 24(4), https://doi.org/10.1177/0957926513482067.

KRESS, G. and T. VAN LEEUWEN (1996): Reading images: The grammar of visual design, New York, Routledge.

LAMBIASE, J. (2003): "Codes of online sexuality: Celebrity, gender and marketing on the Web», Sexuality and Culture, 7(3), 57-78.

LAMPE, C., N. ElLISON and C. STEINFIELD (2007): «A Familiar Face(book): Profile Elements as Signals in an Online Social Network», CHI 2007 Proceedings Online Representation of Self, April 28-May 3, 435-444.

LIPCZYNSKA, S. (2007): «Discovering the cult of Ana and Mia: A review of pro-anorexia websites», Journal of Mental Health, 16(4), 545-548.

LyONS, E.J., M.R. MeHL and J.W. PennebakeR (2006): «Pro-anorexics and recovering anorexics differ in their linguistic Internet selfpresentation», Journal of Psychosomatic Research, 60, 253-256.

Manago, A.M., M.B. Graham, P.M. Greenfield and G. SALIMKHAN (2008): "Self-presentation and gender on MySpace», Journal of Applied Developmental Psychology, 29, 446-45.
Mulveen, R. and J. Hepworth (2006): «An Interpretative Phenomenological Analysis of Participation in Pro-anorexia Internet Site and Its Relationship with Disordered Eating", Journal of Health Psychology, 11, 283-296.

NorRIS, M.L., K. BOYDELL, L. PINHAS and D. KATZMAN (2006): "Ana and the Internet: A review of pro-anorexia websites», International Journal of Eating Disorders, 39(6), 443-447.

PAPACHARISSI, Z. (2002): «The presentation of self in virtual life: characteristics of personal home pages», Journalism and Mass Communication Quarterly, 79(3), 643-661.

QIAN, H. and C.R. ScOTT (2007): «Anonymity and self-disclosure on Weblogs», Journal of Computer-Mediated Communication, 12(4), article 14, 1428-1451, https://doi.org/10.1111/j.10836101.2007.00380.x

RanSON, D.C., J.G. La GuARDIA, E.G. WoOdY and J.L. BOYD (2010): «Interpersonal interactions on online forums addressing eating disorders", Journal of Eating Disorders, 43(2), 443-447.

RILEY, S., K. RODHAM and J. GAVIN (2009): «Doing Weight: Pro-Ana and Recovery Identities in Cyberspace», Journal of Community and Applied Social Psychology, 19, 348-359.

RODGERS, R.F., S. SKOWRON and H. CHABROL (2012): «Disordered Eating and Group Membership Among Members of a Proanorexic Online Community», European Eating Disorders Review, 20(1), 9-12.

ROUleau, C.R. and K. VON RANSON (2010): «Potential risks of pro-eating disorder websites», Clinical Psychology Review, 31(4), 525-531.

SalimkHan, G., A. Manago and P. Greenfield (2010): «The Construction of the Virtual Self on MySpace», Cyberpsychology: Journal of Psychosocial Research on Cyberspace, 4(1), article $1, \quad$ [available at]: http://cyberpsychology.eu/view.php?cisloclan $\mathrm{ku}=2010050203$ \&article $=1$

ShARPE, H., P. Musiat, O. KNAPTON and U. SchmidT (2011): "Pro-eating disorder websites: facts, fictions and fixes», Journal of Public Mental Health,

10(1), https://doi.org/10.1108/174657211111345 $\underline{38}$

SIIBAK, A. (2009): "Constructing the Self through the Photo selection-Visual Impression Management on Social Networking Websites», Cyberpsychology: Journal of Psychosocial Research on Cyberspace, 3(1), [available at]: https://cyberpsychology.eu/article/view/4218/ 3260

SoLEY, L.C. and L.N. REID (1988): «Taking it off: Are models in magazine ads wearing less?», Journalism and Mass Communication Quarterly, 65(4), 960-966. 
StRANO, M. (2008): «User Descriptions and Interpretations of Self-Presentation through Facebook Profile Images», Cyberpsychology: Journal of Psychosocial Research on Cyberspace, 2(2), [available at]: http://cyberpsychology.eu/view.php?cisloclan $\mathrm{ku}=2008110402 \mathrm{andarticle}=1$

StRIFE, S.R. and K. RICKARD (2011): "The Conceptualization of Anorexia: The Pro-Ana Perspective», Affilia, 26, https://doi.org/10.1177/0886109911405592

SYPECK, M.F., J.J. GRAY, S.F. ETU et al. (2006): «Cultural representations of thinness in women, redux: Playboy magazine's depictions of beauty from 1979 to 1999», Body Image: An International Journal of Research, 3, 229-235.

THOMPSON, M. and J. GRAY (1995): «Development and Validation of a New Body-Image Assessment Scale», Journal of Personality Assessment, 64(2), 258-269.
WHITEHEAD, K. (2010): «'Hunger Hurts but Starving Works': A Case Study of Gendered Practices in the Online Pro-eating-disorder Community", Canadian Journal of Sociology/Cahiers canadiens de sociologie, 35(4), 595-626.

WHITTY, M.T. (2007): «Revealing the 'real' me, searching for the 'actual' you: Presentations of self on an internet dating site», Computers in Human Behavior, 24, 1707-1723, https://doi.org/10.1016/j.chb.2007.07.002

Wolf, M., J. SEDWAY, C. BULIK and H. KordY (2007): «Linguistic analyses of natural written language: Unobtrusive assessment of cognitive style in eating disorders», International Journal of Eating Disorders, 40(8), 711-717.

Wolf, M., F. THEIS and H. KORDY (2013): «Language Use in Eating Disorder Blogs: Psychological Implications of Social Online Activity», Journal of Language and Social Psychology, 20(10), 1-15. 